\title{
Perspectives
}

\section{Second-Language Learning Through Imaginative Theory}

\section{Catherine Broom}

This article explores how Egan's (1997) work on imagination can enrich our understanding of teaching English as a second language (ESL). Much has been written on ESL teaching techniques; however, some of this work has been expounded in a standard educational framework, which is what Egan calls an assembly-line model. This model can easily underlie our unconscious structures. The article begins by reviewing Egan's kinds of understanding and then discusses how conceptions of English-language learning may be changed when Egan's Imaginative Education (IE) theory is used as the theoretical base. For example, ESL learning jumps from a simple progression through language levels to multiple and interacting ecological zones that interplay with and within the learner. As well, the focus moves from the generation of activities to the students themselves as conscious, living beings. This theoretical orientation provides possibilities for second-language learning to become wondrous, multifaceted, and intricate.

Cet article étudie les façons dont le travail de Egan (1997) sur l'imagination peut enrichir nos connaissances sur l'enseignement de l'anglais comme langue seconde. Les techniques d'enseignement de l'ALS ont fait coulé beaucoup d'encre et une partie de ce travail est exposée dans un cadre pédagogique standard qu'Egan décrit comme étant un modèle reposant sur les principes de la construction en série. Ce modèle peut facilement constituer la base de nos structures inconscientes. L'article commence par un examen des types de compréhension selon Egan et poursuit avec une discussion des changements dans les conceptions de l'apprentissage de l'anglais langue seconde qui pourraient avoir lieu si on employait la théorie de l'éducation imaginative d'Egan comme base théorique. Par exemple, l'apprentissage en ALS passerait d'une simple progression d'un niveau langagier à un autre à un processus impliquant des zones écologiques qui interagissent dans un jeu réciproque avec l'apprenant. De plus, l'apprentissage ne serait plus axé sur la génération d'activités mais plutôt sur les élèves eux-mêmes comme êtres conscients et vivants. Cette orientation théorique offre des possibilités pouvant transformer l'apprentissage d'une langue seconde en une merveilleuse expérience complexe et variée. 


\section{Egan's Kinds of Understanding}

Egan's (1997) Imaginative Education (IE) theory changes how we understand second-language learning, with implications for classroom practice. It theorizes that students move through various kinds of understanding as they are educated in their sociocultural environments (see Figure 1). Tools tied to language acquisition both encompass and aid in the development of each kind of understanding. These tools are like the physical objects that humans develop to aid them in life such as a pencil or a computer, but they are contained within ourselves; they are tools of and are used by our minds. These tools are developed in and acquired from our cultural environments through education.

For example, according to Vygotsky (2004) from whom this concept is developed, language itself is the ultimate tool. That is, although thinking and language have different origins-humans have both a pre-speech and a pre-intellectual phase, and it is possible to think without words-early in humans' lives at about the age of 2, something interesting happens: speech and thought merge. Suddenly a child begins to think with words, and inner speech develops. From this stage, development is no longer simply natural, but cultural, as words are cultural objects: "verbal thinking is not a natural but a socio-historical form of behaviour" (p. 63).

Conceptual tools are inherent in Egan's (1997) kinds of understanding, the first of which is called the Somatic. At this stage, learning is focused on the body. From a language-learning perspective, this involves students' em-

\begin{tabular}{|c|c|c|c|c|}
\hline $\begin{array}{l}\text { Somatic } \\
\text { Understanding }\end{array}$ & \begin{tabular}{|l|} 
Mythic \\
Understanding
\end{tabular} & $\begin{array}{l}\text { Romantic } \\
\text { Understanding }\end{array}$ & \begin{tabular}{|l|} 
Philosophic \\
Understanding
\end{tabular} & \begin{tabular}{|l|} 
Ironic \\
Understanding
\end{tabular} \\
\hline 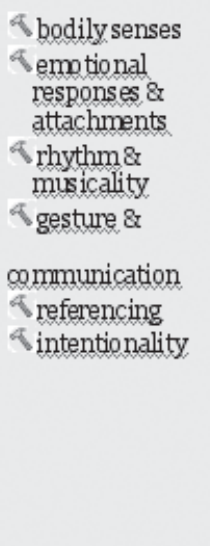 & 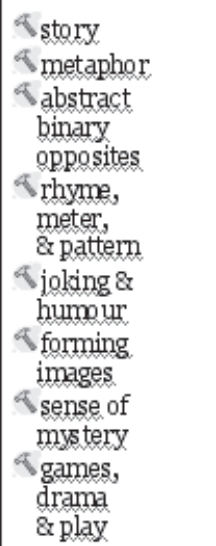 & 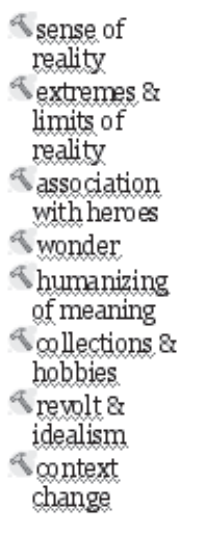 & 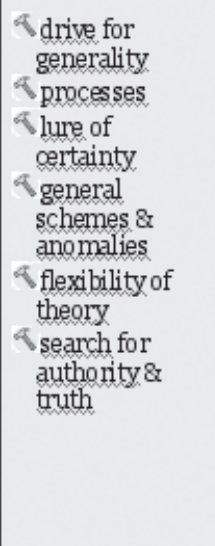 & 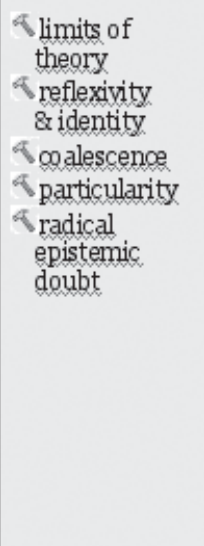 \\
\hline
\end{tabular}

Figure 1. Kinds of understanding and their tools (IERG, 2008). 
bodiment of the language: the appropriation of culturally appropriate gestures or body language and the acquisition of phonetic knowledge of the sounds and rhythms of the language. It is the students' use of their senses, particularly of hearing, that prepares (hardwires) the brain in order to begin the process of language meaning-making. This visceral level focuses on engaging students' emotions. Both emotions and humor are key tools. In effect, they come with our physical bodies and help us to make sense of our world. Emotions interface with the senses in the process of making sense of the physical environment, as well as attaching us to others and to processes such as learning. Humor connects emotions, engagement, and meaning-making. Other tools include using rhythm and associating gestures with actions. Students can be engaged in activities such as cartoon interpretations, songs, pronunciation work, and physical games like "Simon says."

The second stage is the Mythic stage, in which students acquire language. They learn vocabulary with which to make oral speech and understand the words of others. They are able to communicate through words. Here learning vocabulary is crucial, and this can occur through the use of teaching strategies that incorporate cognitive tools, including the use of stories that contain dialectical meanings and emotionally charged content. Such stories are structured in binary opposites, contrasting tensions that engage readers in the narrative. As well, binary opposites can be used to teach what a word is or is not such as hot and cold. Metaphors can also develop vocabulary by associating words with powerful images. Furthermore, the use of humor, games, drama, mystery, and imagery are valuable scaffolds for language-learning and for actively engaging language learners.

Third is Romantic understanding, where students acquire written language. At this stage, students are introduced to reading, writing, and grammar. They can be engaged in language learning through romantic narratives, identification with heroes, as well as the limits and extremes of life: romantic stories are dramatic and human. They explore human potential and its limits. For example, students will be fascinated by Believe it or Not and by dramatic factual accounts in the Guinness Book of Records. Learners will enjoy reading and writing about the achievements of colorful and noteworthy people who have engaged in idealistic actions linked to revolt-people such as Joan of Arc, who inspired a nation to war, giving her own life in the process-or may have fun becoming apprentices of Dr. Frankenstein as they learn about human anatomy (IERG, 2008). They will also appreciate the humanization of potentially monotonous technical processes; for example, the study of grammar can be made fun and effective through the personification of confusing elements such as the difference between to, too, and two (IERG). Students can be engaged by the in-depth study of a subject of interest to them; they can become experts on their hobbies: chefs, art connoisseurs, or hockey fans. 
The next kind of understanding is the Philosophic, in which students begin to develop awareness of the connections between concepts: they acquire laws and theories through which they interpret the world around them. As language learners, they are interested in the grammar of the language, the underlying rules that structure words. They search for the truth about syntax and find comfort in formulas. They enjoy dissecting the form of language. Grammar not only deepens understanding of the language itself, but also improves practical language skills.

Finally, the fifth kind of understanding is called the Ironic: it involves a realization of the limits of theories for interpreting the world and an increasing awareness of the situated nature of each individual's knowledge. Here, language learners engage in complex language use and develop a deeper understanding of a language's flexibility. They become aware that a word may have many connotations and not just one meaning. They understand that grammar rules have exceptions and realize that all languages are sociocultural constructions that provide a particular and limited understanding of the world.

\section{Complex Language-Learning}

Chronologically, for any young learner, each kind of understanding unfolds from the previous one, and the use of its cognitive tools engages students imaginatively in learning. However, in the particular case of second-language learning, the situation is more complex. Although the kinds of understanding have links to English-language levels by matching a progression of activities based on teaching cognitive tools that provide scaffolding for higher levels of language and thought, students reach the classroom having already completed many of these kinds of understanding in their own language-learning experience. Thus IE bridges both learner-centered and learning-centered approaches to teaching a second language. Language learners are not viewed as empty vessels: it is recognized that students have already acquired a number of conceptual tools that can either aid learning or hinder it by the incorrect application of culturally contingent rules. In other words, through the use of cognitive tools, language learners, particularly older ones, can be engaged simultaneously in all the kinds of understanding including stories, metaphors, dialogues, debates, mystery, and humor (see Figure 1).

Second-language teaching is thus multifaceted: although in a sense students progress through English-language-learning stages in a linear manner, they in fact already possess many conceptual tools that can aid them in learning and on which the teacher can draw to enrich language lessons. These tools are encompassed in the multiple kinds of understanding that students have acquired in their own lifetimes that coexist and interrelate with each other in an individual and that potentially interrelate with other culturally contingent kinds of understanding. As illustrated in Figure 2, the kinds of 


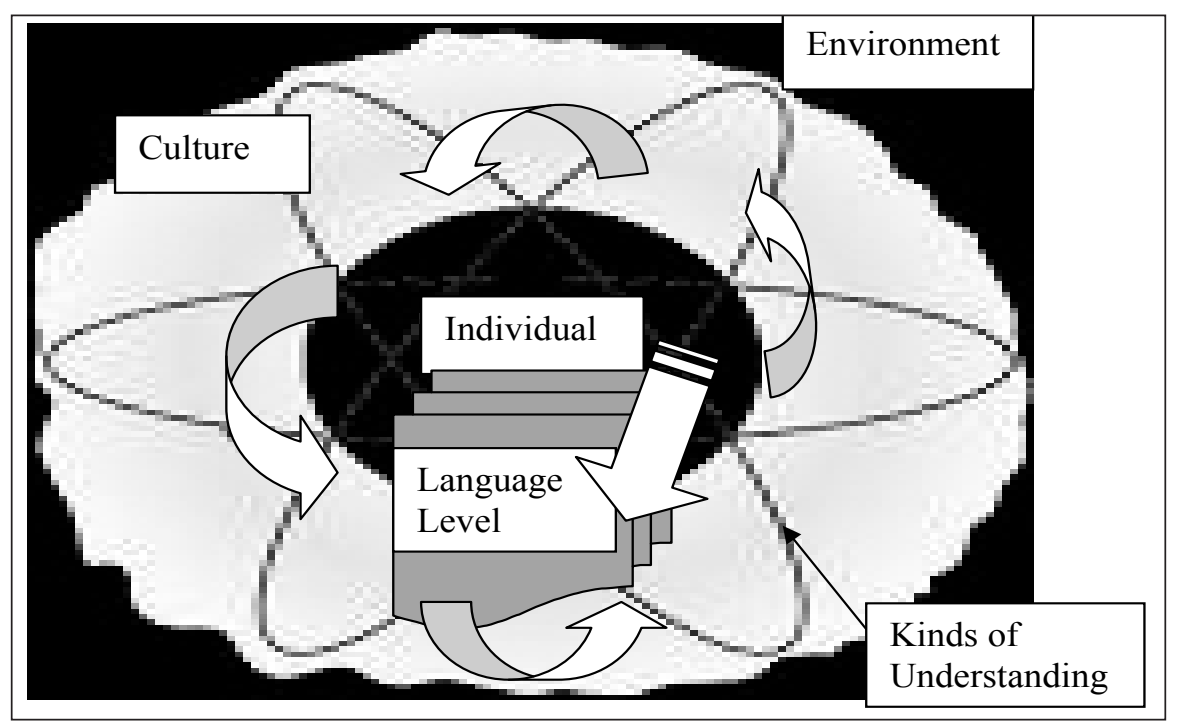

Figure 2: Language learning within multiple kinds of understanding.

understanding are like ecological zones in that they all exist simultaneously in varying forms in adults and influence language learning. In addition to these, the figure illustrates how each individual is also embedded in particular environments and is shaped in and through a particular (or several) culture(s). Individuals are also unique in that they possess varying personalities and varying levels of language proficiency.

IE thus rejects the linear, industrial approach to learning as reflected, for example, in the well-known Taylor (Wertsch, 2002) rationale, which often becomes an unacknowledged schematic narrative template that influences how lessons are conceived and taught. A schematic narrative template is an embedded way of thinking that affects how a teacher may view and then teach his or her students. Imaginative theory aims to break away from such linearity by postulating that kinds of understanding may exist at all levels of language-learning in varying ways. All the kinds of understanding contain beneficial features, and they can work together in aiding (and hindering) language-learning.

The process of acquiring a new language is not an assembly-line progression in which teachers must move from simple to more complex activities. As language learners may already have mastered many of these understandings (and others), rich possibilities for lessons exist: all the cognitive tools embedded in the kinds of understanding should be valued and can be used to teach all levels of language proficiency. Thus advanced language learners will still benefit from embodied learning such as the use of music, rhythm, 
and dance. Students from cultural groups, who traditionally may not view these activities as aiding in language-learning, may come to recognize their value in both enhancing learning and engaging learners. New language learners will appreciate the use of humor (even in graphic form), the cultivation of a hobby in the new language, or learning the multiple connotations of a word. Students may seem to be progressing in a linear fashion through the acquisition of language, but language levels interact with students' ages (and associated cognitive tools), with the result that a multidimensional approach to lesson design is enriching. Drawing on the tools for all kinds of understanding can promote lesson design that deepens, enriches, and enlivens learning.

IE has further implications for language-learning. As it draws on socioconstructivist thinking as in Vygotsky's (2004) work, it views the sociocultural environment around the student as particularly important. This means that (a) the actions of the teacher in the classroom are significant, and (b) students' language-learning is shaped by their sociocultural backgrounds. Regarding the first point, teachers should take care to ensure that they create welcoming and engaging environments using IE tools (as advocated by Lozanov, 1978, for Suggestopedy). Teachers should also develop positive relationships with their students and push them to higher levels of languagelearning through the creation of a zone of proximal development (Vygotsky), that is, by providing activities that are a little more difficult than the students' current language levels. With respect to the second point, teachers need to become familiar with the students whom they are teaching, especially in relation to the kinds of understanding that are most relevant to them and their individual personalities.

Teachers can identify which kinds of understanding their students have acquired by analyzing their cognitive tools (see Figure 1), that is, by identifying students' language use in their native languages. All who have oral skills can be considered to have the Mythic toolkit available, and those who are able to read and write in their native languages would be at the Romantic or even the Philosophic level if they are able to understand and work within general theories. Those who can reflect on these would be at the Ironic kind of understanding. The students' kinds of understanding will be separate from their knowledge of English. Teachers need to keep in mind that kinds of understanding are not developmental stages through which students move. Rather, students add new kinds of understanding as they mature. All kinds of understanding with their related tool kits remain and can be drawn on by teachers to enrich second-language learning.

Although IE theorizes that individuals' minds are shaped by their cultures, individuals are not considered simply to be socially determined. Rather, individual abilities, personalities, and character are recognized as interacting with the process of development dialectically, as theorized in con- 
structivism and as illustrated in Figure 2. Teachers should thus develop lessons that draw on their individual students' personalities and abilities. For example, students who exemplify leadership abilities should be given leadership roles in the classroom. Those who love art should be able to choose a topic related to that interest to study in depth.

In addition, this approach acknowledges that although most literate cultures may have similar kinds of understanding and thus similar tools, some may also have developed other forms or elements in terms of their kinds of understanding and cognitive tools. For example, one of Vygotsky's (2004) followers found that nonliterate societies did not perceive the natural space around them as did those from a literate society. This kind of insight creates a need for teachers to understand the tools that their students have acquired in their own cultures and the roles that these play in shaping their current language-learning. A simple example is how the syntax and grammatical rules of the first language can underlie and structure how a new language is learned. It is almost as if the first language is a schematic narrative template that shapes the acquisition of the new language. Consider how difficult English articles and word order are for Japanese students. This is not surprising when one considers that unlike English, the Japanese language has no articles and places verbs at the end of the sentence. Other factors to keep in mind are students' ages and levels of education and literacy.

IE theory identifies challenges for classrooms structured around students of varied ages. This often occurs if students are grouped by language level rather than by age. As students of varied ages may be situated in varied kinds of understanding - as well as possessing varied cultural cognitive toolsteachers are presented with particularly challenging lesson-planning situations. Possible solutions are to divide students into classes by the cognitive tools or kinds of understanding that they possess, as well as comparable language levels, and then to engage them with the tools almost (or actually) possessed by most of the students in order to challenge them to higher levels of learning. In situations where classes with mixed language levels, ages, and kinds of understanding cannot be avoided, teachers can divide students into small groups with lessons to match varying abilities and prepare lessons that include activities of varying language-level difficulties along with varying kinds of understanding. As well, the Community Language Learning approach (as popularized, among others, by Stevick, 1980) could be used in modified form with students at higher levels of language proficiency who possess Philosophic or Ironic kinds of understanding in order to have students explore through discussion the varying ways that they engage in meaning-making in English and the challenges they face due to their varied cultural backgrounds. 


\section{The Importance of Culture}

Language learning is understood to be cultural in two ways. First, culture embeds within itself integrated patterns of knowledge, belief, and action, which are expressed and realized through the language acquired by individuals: "Culture, then, though itself man-made, both forms and makes possible the workings of a distinctly human mind. On this view, learning and thinking are always situated in a cultural setting and always dependent upon the utilization of cultural resources" (Bruner, 1996, p. 4). Language is both a tool and a shaper of cultural patterns and the mind. Thus a child's learning progresses from the outside in, from society to the individual, through a process of dialogue using language, the ultimate social tool (Vygotsky, 2004). According to Vygotsky, over time and through dialogue, the child's mental processes become ordered and logical and develop into higher forms of thought such as reflection. Children are thus shaped by their history and society through language, but are then able to free themselves from it by the tool of language. The role of the teacher in this model is to engage the student in continual and increasingly more complex dialogues in order to expand his or her learning in Vygotsky's zone of proximal development.

Second, culture is the foundation of cognitive tools and of learning, but it is not understood to be a closed system. Quite the opposite: culture is fluid, organic, and ever-changing as it integrates new elements and repudiates others: "culture ... is ... dynamic; multifaceted; embedded in context; influenced by social, economic, and political factors; created and socially constructed; learned; and dialectical" (Nieto, 2002, p. 11). Consequently, learning a second language deepens understanding of the students' first culture and of other cultures, which is why classrooms should include students of varied cultural backgrounds. As language is a tool and a product of culture socialized into the mind, new language-learning (embedded in its culture) reshapes students' understandings of their own cultures and of their own minds, helping them to grow to new understandings of life. Perhaps this is why those who speak two languages have been shown through research to have brains that age better than the brains of those who speak only one language (Bialystok, 2007). Learning another language restructures (and thus broadens) the mind through the formation of new meaning; second-language learning draws on and then further refines and develops (or adds new) kinds of understanding and their associated tools. Teaching students of multiple cultures together is challenging but enriching for all.

\section{From Theory to Practice}

The implications are that language-learning is understood to be embedded in culture, learning style/personality, and age. Teachers should understand their students and plan lessons that are appropriate for them. They do this 
by identifying which of the kinds of understanding their students use most energetically and then using the tools of these kinds of understanding to plan varied, interactive, and engaging lessons. They can divide students into varied lessons depending on the kinds of understanding they possess as well as on their language-level proficiency. For example, perhaps a teacher will identify his or her students as being low-intermediate language learners, but at the philosophic kind of understanding. He or she can thus engage them through teaching vocabulary to learn about the grand processes of historical change, the varied theoretical interpretations of language itself and its contingent grammar, and the intricacies and complexities of language as illustrated in the multiple meanings of words. At the same time, in lesson-planning, he or she can draw on tools from the previous kinds of understanding such as songs and poems, drama, solving mysteries, and reading stories. He or she can also spur the students on to higher, more flexible language use by introducing reflection on their own language, the new language they are learning, and the meanings of culture and language themselves. He or she can compare the language structures of the first language with those of the new language. As the teacher gets to know the students and their cultures, he or she can explore whether they have other tools not listed in Figure 1 and integrate these into teaching - this is a rich area for research.

\section{Note}

This article was written by a former Imaginative Education Research Group (IERG) research assistant, after dialogue with Kieran Egan on the implications of Imaginative Education for Second Language Learning. Egan read and commented on the article. Further information on Imaginative Education is available in Egan (1997) and in IERG (2008).

\section{The Author}

Catherine Broom is an assistant professor at the University of British Columbia, Okanagan. She has more than 15 years of high school teaching experience in Canada and overseas. She completed her doctorate at Simon Fraser University in 2007. She is interested in the history of the development of modern schooling; postmodern theories and methods including imaginative education; the meaning of culture and education in a pluralist nation; and social studies history, methods, and philosophies. She has written and published on the meaning, history, and methods of social studies, local and global citizenship, and ecological consciousness.

\section{References}

Bialystok, E. (2007). Bilingualism as a protection against the onset of symptoms of dementia. Neuropsychologia, 45(2), 459-464.

Bruner, J. (1996). The culture of education. Cambridge, MA: Harvard University Press.

Egan, K. (1997). The educated mind: How cognitive tools shape our understanding. Chicago, IL:

Chicago University Press.

IERG. (2008). Imaginative Education Research Group. Retrieved January 28, 2011, from:

http://www.ierg.net

Lozanov, G. (1978). Suggestology and outlines of suggestopedy, New York: Gordon \& Breach.

Nieto, S. (2002). Language culture and teaching: Critical perspectives for a new century.

Mahwah, NJ: Erlbaum. 
Stevick, E. (1980). Teaching languages: A way and ways. Rowley, MA: Newbury House.

Vygotsky, L.S. (2004). The essential Vygotsky (R.W. Rieber \& D.K. Robinson, Eds.). New York: Kluwer Academic.

Wertsch, J.V. (2002). Voices of collective remembering. Cambridge, UK: Cambridge University Press. 